Ditzel, J., and Schwartz, M. (1967). Diabetes, 16, 264.

Emerson, K., jun., and Dole, V. P. (1943). Fournal of Clinical Investigation, 22, 447.

Froesch, E. R., Reardon, J. B., and Renold, A. E. (1957). fournal of Laboratory and Clinical Medicine, 50, 918.

Hemmingsen, L., Hoiby, N., and Kragh-Søtensen, P. (1970). Diabetologia, 6, 512

Higashi, A., and Peters, L. (1950). Fournal of Laboratory and Clinical Medicine, 35, 475

Jorgensen, M. B. (1967). Acta Medica Scandinavica, 181, 153.

Keen, H., and Chlouverakis, C. (1964). Lancet, 2, 1155.

Lambert, P. P., Gassee, J. P., and Askenasi, R. (1970). In Proteins in Normal and Pathological Úrine, p. 67. Basel, Karger.

Latotzki, H. (1958). Zeitschrift für klinische Medizin, 155, 158.

Latotzki, H. (1964). In Diabetische Angiopathie, p. 81. Berlin, Akademie.

Lazarow, A. (1964). In Small Blood Vessels Involvement in Diabetes Mellitus, p. 9. Washington, D.C., American Institute of Biological Science.

Lowry, O. H., Rosebrough, N. J., Farr, A. L., and Randall, R. J. (1951). fournal of Biological Chemistry, 193, 265.

Lundbaek, K., et al. (1970). Lancet, $2,121$.

Ørskov, H., Thomsen, H. G., and Yde, H. (1968). Nature, 219, 193.

Orsterby-Hansen, R. (1965). Diabetologia, 1, 97.

Osterby-Hansen, R. (1971). In Microcirculatory Approaches to Curren Therapeutic Problems, p. 142. Basel, Karger.
Panzram, G., Anger, G., and Wöllner, H. (1967). Deutsche medizinische Wochenschrift, 92, 1013.

Pauli, H. G., Truniger, B., Larsen, J. K., and Mulhausen, R. O. (1968) Scandinavian fournal of Clinical and Laboratory Investigation, 22 Suppl. No. 103, p. 55

Ram, M. D., Evans, K., and Chisholm, G. D. (1967). Lancet, 2, 645.

Robertson, J. A., Grey, C. H., and Baynes, A. H. (1951). Archives of Internal Medicine, 87, 570

Sapirstein, L. A., Vidt, D. G., Mandel, M. J., and Hanusek, G. (1955) American fournal of Physiology, 181, 330.

Sims, E. A. H. (1961). Diabetes, 10, 190.

Smith, H. W., Chasis, H., Goldring, W., and Ranges, H. A. (1940). Fournal of Clinical Investigation, 19, 751 .

Smith, H. W., Finckelstein, N., Aliminosa, L., Crawford, B., and Braber, $M$. (1945). Fournal of Clinical Investigation, 24, 388.

Spühler, O. (1946). In Zur Physio-Pathologie der Niere, p. 45. Bern, Hans Huber.

Stalder, G. R., Schmid, R., and Wolff, M. V. (1960). Deutsche medizinische Wochenschrift, 85, 346 .

Teuscher, A., and Zahnd, G. (1970). Excerpta Medica. International Congress Series, 209, 141 .

Thomsen, A. C. (1965). The Kidney in Diabetes Mellitus, p. 72. Copenhagen, Munksgaard.

Tojo, S., Tsuchiya, T., and Yokota, S. (1965). Tonyobyo, 8, 239.

\title{
Sucrose Malabsorption in Greenland
}

\author{
A. MCNAIR， E. GUDMAND-HØYER， S. JARNUM， LIS ORRILD
}

British Medical fournal, 1972, 2, 19-21

\section{Summary}

In a population study on the western coast of Greenland the incidence of sucrose malabsorption was estimated by means of sucrose tolerance tests in 190 persons. Smallintestinal disaccharidase activity was estimated in 19 patients. Sucrose malabsorption was present in $10.5 \%$ of the cases studied-a surprisingly high figure and much higher than the incidence reported elsewhere in the world. This incidence is, however, lower than that of lactose malabsorption in Greenland Eskimos (54\%). In contrast to lactose malabsorption, sucrose malabsorption is present from birth; this may have important clinical implications since chronic diarrhoea and malnutrition are fairly common during infancy in Greenland.

\section{Introduction}

Lactase deficiency of the small-intestinal mucosa is not unusual in the adult population of the Western World and, in fact, it seems to be the normal condition in large population groups of the Asian and African continents.

In contrast, sucrose malabsorption, which is always associated with isomaltose malabsorption, occurs sporadically and with much lower frequency than lactose malabsorption. Though occasionally occurring on a hereditary basis sucrose malabsorption has so far not been reported to be confined to or abnormally prevalent in certain ethnic groups.

In Greenland Eskimos lactose malabsorption occurs in more than $50 \%$ of adults and is first noted from about the 6th year of life (Gudmand-Høyer et al., 1972). This figure is based on a population study carried out in three districts of the western coast of Greenland in 1970-1. The primary aim of the study was to establish the incidence of lactose malabsorption and to

\footnotetext{
Medical Department P, Division of Gastroenterology, Rigshospitalet, DK-2100 Copenhagen

A. MCNAIR, CAND. MED.

E. GUDMAND-HEYER, M.D.

S. JARNUM,

LIS ORRILD, CAND. MED.
}

ascertain its nutritional and clinical significance, if any. In most of the subjects studied, however, the lactose tolerance test was supplemented with a sucrose tolerance test. The results of the latter test form the basis of the present report. They suggest that the incidence of sucrose malabsorption is higher among Greenland Eskimos than among other populations so far studied.

\section{Methods}

The sucrose tolerance tests were carried out with an oral load of sucrose $(50 \mathrm{~g}$ of sucrose dissolved in water for adults, $1.5 \mathrm{~g} / \mathrm{kg}$ for children) given to fasting subjects. Blood sugar determinations by a glucose oxidase method were made on capillary blood before sucrose administration and 15,30, 45, and 60 minutes later. Inquiries were made about diarrhoea and abdominal distress (colic, bloating, borborygmi) during and after the test.

The conditions of the study did not permit a subsequent tolerance test with a mixture of glucose and fructose, the monosaccharide components of sucrose. Instead, the blood sugar rise during a lactose tolerance test was used for comparison or, in the presence of lactose malabsorption, the blood sugar rise during a glucose-galactose tolerance test. A maltose tolerance test was performed in a few cases.

Where possible questions were asked about drinking and eating habits and whether milk or sugar-for instance, sweetswere avoided and for what reasons. Relatives of children were asked about the childrens' growth during infancy and whether they suffered or had suffered from chronic diarrhoea and malnutrition. If so, an attempt was made to establish a time relationship between these symptoms and a change of dietfor instance, supplementation of breast-feeding with sucroseenriched cows' milk.

The enzyme activity of maltase, isomaltase, sucrase, trehalase, and lactase was determined in small-intestinal biopsy samples from the jejunum at or immediately distal to Treitz's ligament. The analyses were performed by A. Dahlquist, Lund, Sweden. The results are reported in detail elsewhere (Asp et al., 1972).

Diagnostic Criteria.-A diagnosis of sucrose malabsorption was accepted if the maximum blood sugar rise during a sucrose tolerance test was less than $25 \mathrm{mg} / 100 \mathrm{ml}$ and the ratio between the maximum rises after sucrose and after glucose-galactose or lactose was less than $\mathbf{0 . 4 0}$. 


\section{Subjects}

Sucrose and lactose tolerance tests were made on 190 volunteers (103 females, 87 males). They were selected from patients and their relatives at the local hospitals in the three districts studied (Jakobshavn, Holsteinsborg, Godthåb) and from the hospital staff and their relatives. A local interpreter informed them about the purpose of the investigation and the procedure of the sugar tolerance tests.

Small-intestinal biopsy specimens were obtained from 19 patients admitted to Dronning Ingrid's Hospital in Godthåb for a variety of diseases, few involving the gastrointestinal tract.

\section{Results}

Sucrose malabsorption was present in $20(10.5 \%)$ of the 190 Eskimos studied. The diagnosis in every case except one (Case 20) could be based on a maximum blood sugar increase of less than $25 \mathrm{mg} / 100 \mathrm{ml}$ (see Chart). In Case 20 the sucrose tolerance test could not be completed because the subject vomited after the ingestion of sucrose. However, his small-intestinal sucrase activity was abnormally low (see Table II). In 18 cases the ratio between the maximum blood sugar rise after the sucrose tolerance test and after the lactose or glucose-galactose tolerance

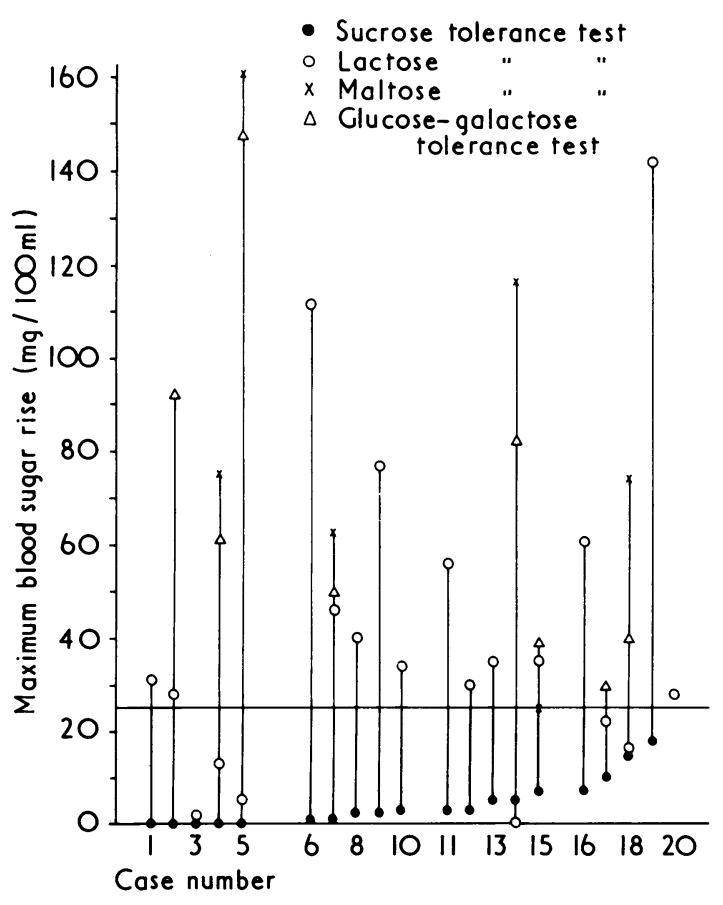

Tolerance tests in 20 Eskimos with sucrose malabsorption.

TABLE I-Incidence of Sucrose Malabsorption in 190 Greenland Eskimos

\begin{tabular}{|c|c|c|}
\hline Age in Years & No. Studied & No. with Sucrose Malabsorption \\
\hline $\begin{array}{cc}\text { Under } 2 & \ldots \\
2-5 & \ldots \\
6-14 & \cdots \\
15-24 & \therefore \\
25 \text { and over } & \ldots\end{array}$ & $\begin{array}{r}4 \\
27 \\
51 \\
23 \\
85\end{array}$ & $\begin{array}{l}4(100 \%) \\
3(11 \%) \\
5(10 \%) \\
3(13 \%) \\
5(6 \%)\end{array}$ \\
\hline Total & 190 & $20(10 \cdot 5 \%)$ \\
\hline
\end{tabular}

TABLE II-Disaccharidase Activities (IU/g of Protein) in Small-intestinal Biopsy Specimens from Three Greenland Eskimos with Sucrose Malabsorption

\begin{tabular}{cc|c|c|c|c|c}
\hline \multicolumn{2}{c|}{$\begin{array}{c}\text { Case } \\
\text { No. }\end{array}$} & $\begin{array}{c}\text { Sucrase } \\
(26-138)\end{array}$ & $\begin{array}{c}\text { Isomaltase } \\
(25-183)\end{array}$ & $\begin{array}{c}\text { Lactase } \\
(9-98)\end{array}$ & $\begin{array}{c}\text { Maltase } \\
(111-420)\end{array}$ & Trehalase \\
\hline 12 & $\cdots$ & $<0.5$ & 1.4 & 4.3 & 56 & 28 \\
14 & $\cdots$ & $<0.6$ & 1.1 & 1.9 & 43 & 14 \\
20 & $\cdots$ & $<0.6$ & 1.5 & 4.0 & 92 & 20 \\
\hline
\end{tabular}

test was less than $\mathbf{0} \cdot 40$. In Case 3 (see Chart) the ratio was not applicable because only the sucrose and lactose tolerance tests were performed and the subject turned out to have both sucrose and lactose malabsorption.

Sucrose malabsorption was found in four infants aged 15 to 21 months and in 11 out of 101 subjects aged 2 to 24 years, whereas it occurred in only $5(6 \%)$ out of 85 adults aged 25 to 65 years (Table I).

The incidence of sucrose malabsorption in the 108 subjects aged 15 and over was compared with that in a control series of 204 Danish patients consecutively subjected to small-intestinal biopsies at this department within the past 2 years ( 33 were aged 15 to 24 years and 171 were 25 and over). There was a highly significant difference $\left(\chi^{2}=14.66, P<0.001\right.$ with the Yates's correction) between the Greenlanders and Danish patients, among whom no case of isolated sucrose malabsorption was registered.

Racial "purity" could be assessed in 17 subjects with sucrose malabsoprtion. Eleven were pure Eskimos and six had a Danish ancestor three to six generations previously. A hereditary factor was suggested by the fact that sucrose malabsorption was present in a mother and her son and in two siblings and their cousin and in another cousin's child.

Simultaneous lactose malabsorption was present in six casesfive females aged 13 to 65 years and a boy aged 21 months. The incidence of lactose malabsorption was thus $30 \%$, which is appreciably lower than the $54 \%$ found in a study of 220 Eskimos reported by Gudmand-Hoyer et al. (1972). This difference, however, is not significant $(P>0 \cdot 10)$.

Small-intestinal Enzyme Activity.-In 3 (16\%) of the 19 small-intestinal biopsy specimens a pronounced deficiency of sucrase $(<0.6 \mathrm{IU} / \mathrm{g}$ of protein) and isomaltase $(1 \cdot 1-1.5 \mathrm{IU} / \mathrm{g}$ of protein) was found (Table II). The three patients (Cases 12, 14, and 20) were also deficient in respect of mucosal lactase activity. The sucrose tolerance test produced diarrhoea in two cases. Their maximum blood sugar rise was abnormally low (see Chart). The third patient vomited after the sucrose ingestion. In the remaining 16 subjects the sucrase-isomaltase content was normal. The sucrose tolerance test showed nothing abnormal in all but one of these subjects, on whom the test was not performed.

Symptoms during Sucrose Tolerance Test.-During and after the sucrose tolerance test only 10 of the patients with sucrose malabsorption had diarrhoea, which in three instances was associated with abdominal pains.

Clinical Significance of Sucrose Malabsorption.-On inquiry, eight subjects denied gastrointestinal complaints. Five of them had no symptoms during the sucrose tolerance test and the other three had diarrhoea. The remaining 12 subjects with sucrose malabsorption all had chronic or intermittent diarrhoea. One was a 65-year-old woman, while the others were children aged 15 months to 16 years (average 6 years). In eight patients diarrhoea developed during infancy when sucrose-enriched cows' milk was substituted for breast-feeding. Six patients reported diarrhoea; in five this was associated with abdominal pains occurring after the ingestion of cane sugar and sweets. In three children severe malnutrition was observed during their first year of life when they were fed cows' milk with added sugar. One of them, who represented the severest case, spent a year and a half in hospital from the 10th week of life. He was the only one to suffer both sucrose and lactose malabsorption. As a result of the present study he was put on a diet with sucrose and lactose restriction, which led to a rapid improvement including a weight gain of $2 \mathrm{~kg}$ in the course of one month.

\section{Discussion}

Sucrose malabsorption is rare and has so far been observed only in sporadic cases. In the present study an overall incidence of sucrose malabsorption of $10.5 \%$ was observed in 190 Greenland 
Eskimos. In 1961 Jensen briefly reported the occurrence of sucrose malabsorption in a female Greenlander (with a Danish spouse) and her three children. His observations attract new interest in view of our findings. Though a certain selection in our case material was inevitable, since several infants were referred to the study group because of unexplained diarrhoea, the number of cases with sucrose malabsorption far exceeded the incidence expected from other studies.

Nevertheless, the incidence of lactose malabsorption in Greenland is much higher, from 54 to $88 \%$ depending on the racial purity of the subjects studied (Gudmand-Høyer et al., 1972). However, lactase deficiency is a feature which Greenlanders share with the majority of the populations in Asia and Africa (Rosensweig, 1971), whereas a $10 \%$ incidence of sucrose malabsorption does not seem to have been reported from anywhere else in the world.

One may speculate whether the fact that man in the Arctic regions has sustained himself on predominantly animal food for thousands of years may have tended to deprive him of sucraseisomaltase as a "negative" adaptive response, since sucrose and isomaltose (in starch) are of vegetable origin. Similarly, no need has existed for lactase activity after the weaning period until recently, because dairy products cannot be processed in the Arctic climate.

Lactase deficiency in Greenlanders seems to arise in childhood after the weaning period (Gudmand-Hфyer et al., 1972). In contrast, sucrose malabsorption apparently exists from birth. It may have important clinical consequences in early life. Thus three of the infants studied by us presented with chronic diarrhoea and severe malnutrition. In the most severe case the patient spent 18 months in hospital from the 10th week of life. $\mathrm{He}$ was the only infant to suffer both sucrose and lactose malabsorption. When these diagnoses were established (as a result of the present investigation) he was put on a lactosesucrose-poor diet, which led to a rapid improvement.

The death rate from "enteritis" among infants below 1 year of age in Greenland is several times higher than in Denmark. Hitherto unrecognized sucrose malabsorption may be a contributory cause of this difference or the reason for it.

Among the older children and adults with sucrose malabsorption in this study half (8) suffered from chronic or intermittent diarrhoea. In several instances diarrhoea started during infancy when cows' milk enriched with cane sugar was given. A few subjects had noticed that sweets produced diarrhoea. The fact that almost half of the subjects in this series had no gastrointestinal complaints despite regular sucrose consumption is not extraordinary. A similar observation was made by Anderson et al. (1963). Similarly, it is well known that lactase-deficient individuals often tolerate even fairly large amounts of milk without any distress.

This work was supported by grants from Den Lægevidenskabelige Forskningsfond for Storkøbenhavn, Færøerne og Grønland, P. Carl Petersens Fond, and the Danish Foundation for the Advancement of Medical Science.

\section{References}

Anderson, C. M., Messer, M., Townley, R. R. W., and Freeman, M. (1963). Pediatrics, 31, 1003.

Asp, N.-G., et al. (1972). To be published.

Gudmand-Høyer, E., McNair, A., and Jarnum, S. (1972). To be published.

Jensen, P. E. (1962). Acta Paedicatrica Scandinavica, 51, 227.

Rosensweig, N. D. (1971). Gastroenterology, 60, 464.

\title{
Outpatient Treatment Trial of Mild and Severe Hypertension
}

\author{
K. L. STUART, C. MACIVER, J. A. NICHOLSON
}

British Medical fournal, 1972, 2, 21-24

\section{Summary}

Not much is known about the feasibility or the advantages of treatment of subjects with only mild hypertension. There are also many unresolved problems in the outpatient management of hypertension of any severity. In this study an analysis is made of the results of a controlled treatment trial of 56 subjects with mild hypertension, 26 of whom were treated with active drug and 30 initially with placebo, and a treatment programme involving 81 patients with moderate or severe hypertension, all of whom received treatment with active drug. The drugs used in this study were bethanidine, debrisoquine, and guanethidine.

Follow-up for 12 months or more was achieved in $87 \%$ of individuals admitted to the study with mild hypertension and in $80 \%$ with severe hypertension. Many subjects with only mildly raised blood pressure were found to have cardiac enlargement on chest $x$-ray (up to

Department of Medicine, University of the West Indies, and University Hospital, Jamaica

K. L. STUART, F.R.C.P., Professor of Medicine

C. MACIVER, M.R.C.P., Consultant

J. A. NICHOLSON, M.R.C.P., Senior Registrar

$45 \%$ ) and left ventricular hypertrophy on electrocardiogram (up to $51 \%$ ). Rapid rates of rise of blood pressure were observed in many placebo-treated subjects; but good blood pressure control was achieved in 63 out of 104 patients $(61 \%)$ receiving active drug in both the mild and the severe hypertension groups. The drugs used showed approximately equal effectiveness in controlling blood pressure.

\section{Introduction}

Clinical medicine has tended to concern itself principally with the treatment of the complications or catastrophic end-stages of chronic diseases rather than with their prevention. The patient with heart attack or stroke is treated but little is done to reduce the frequency of these occurrences, although there is adequate evidence that early recognition and effective and sustained treatment of hypertension would achieve this.

That hypertension is one of the commonest and most potent precursors of cardiovascular disease is beyond doubt. Nor is there any reason to dispute that patients with either severe or moderate hypertension benefit from treatment. What is not so well known is whether and to what extent the same benefits may accrue from the treatment of mild hypertension before organ damage has occurred. Freis (1969) pointed out that it is here that the greatest potential for lowering hypertensive 